\title{
Morte encefálica e cuidados na manutenção do potencial doador de órgãos e tecidos para transplante
}

\author{
Brain death and care in maintaining the potential of organ and tissue transplant donors
}

Muerte encefálica y cuidados en el mantenimiento del potencial donante de órganos y tejidos para transplante

Izaura Luzia Silvério Freire ${ }^{1}$, Ana Elza Oliveira de Mendonça² ${ }^{2}$ Vamilson Oliveira de Pontes ${ }^{3}$, Quinídia Lúcia Duarte de Almeida Quithé Vasconcelos ${ }^{4}$, Gilson de Vasconcelos Torres ${ }^{5}$

\section{RESUMO}

Este trabalho trata-se de estudo exploratório-descritivo com abordagem quantitativa e dados prospectivos que objetivou verificar o conhecimento dos profissionais de enfermagem sobre a Morte Encefálica (ME) e a manutenção do Potencial Doador (PD). A população constou de 55 profissionais de enfermagem. Destes, a maioria eram técnicos em enfermagem (74,5\%); $78,2 \%$ informaram já ter trabalhado com PDs e 50,9\% afirmaram estar preparados para cuidar desses pacientes. Das condições indispensáveis para a abertura do protocolo de $\mathrm{ME}, 49,1 \%$ afirmaram erroneamente a temperatura superior a $36^{\circ} \mathrm{C}$. No manejo dos distúrbios hidroeletrolíticos, 50,9\% optaram incorretamente sobre a reposição de sódio, potássio e magnésio. Nos cuidados com córneas, 58,2\% optaram erradamente sobre a proteção com gaze. E 52,7\% afirmaram corretamente que o PD pode ser reanimado. $O$ conhecimento sobre o diagnóstico de ME e manutenção ao PD era insuficiente entre os pesquisados, necessitando de educação sobre o tema a fim de aumentar a oferta de órgãos/tecidos para transplantes.

Descritores: Enfermagem; Morte Encefálica; Transplante; Unidade de Terapia Intensiva.

\section{ABSTRACT}

This is an exploratory-descriptive study performed using a quantitative approach and prospective data, with the objective to identify the knowledge of nursing professionals regarding brain death (BD) and maintaining the Potential Donor (PD). The study population consisted of 55 nursing professionals, mostly nursing technicians (74.5\%); 78.2\% reported having worked with PDs and 50.9\% stated being prepared to take care of those patients. Among the conditions considered indispensible to open a BD protocol, $49.1 \%$ made a wrong statement of body temperature above $36^{\circ} \mathrm{C}$. Regarding the management of hydroelectrolytic disorders, $50.9 \%$ made a wrong choice concerning the reposition of sodium, potassium and magnesium. Regarding cornea care, 58.2\% made a wrong decision about the protection using gauzes. Furthermore, $52.7 \%$ made the correct statement that the PD can be reanimated. It was observed that the subjects had insufficient knowledge regarding the diagnosis of BD and PD maintenance, thus requiring education on the topic in order to increase the offer of organs/tissue for transplants.

Descriptors: Nursing; Brain Death; Transplantation; Intensive Care Units.

\section{RESUMEN}

Estudio exploratorio, descriptivo, cuantitativo, con datos prospectivos, objetivando verificar el conocimiento de los profesionales de enfermería sobre Muerte Encefálica (ME) y el mantenimiento del Potencial Donante (PD). Población constituida por 55 profesionales de Enfermería. La mayoría (74,5\%), técnicos de Enfermería; 72,8\% refirió haber trabajado con PDs y 50,9\% afirmó estar preparado para cuidar de tales pacientes. De las condiciones indispensables para apertura de protocolo de ME, 49,1\% mencionó erróneamente temperatura superior a $36^{\circ} \mathrm{C}$. En el manejo de disturbios hidroelectrolíticos, 50,9\% optó incorrectamente sobre la reposición de sodio, potasio y magnesio. En el cuidado de córneas, 58,2\% sugirió erróneamente sobre protección con gasas. Finalmente, 52,7\% afirmó correctamente que el PD puede ser reanimado. El conocimiento sobre diagnóstico de ME y mantenimiento del PD fue insuficiente entre los investigados, necesitando ellos de educación sobre el punto, a efectos de aumentar la oferta de órganos y tejidos para transplantes.

Descriptores: Enfermería; Muerte Encefálica; Trasplante; Unidades de Cuidados Intensivos.

\footnotetext{
${ }^{1}$ Enfermeira, Mestre em Enfermagem. Discente do Programa de Pós-Graduação em Enfermagem (PGENF) da Universidade Federal do Rio Grande do Norte (UFRN), nível Doutorado. Professora Assistente da UFRN. Natal, RN, Brasil. E-mail: izaurafreire@hotmail.com.

${ }^{2}$ Enfermeira, Mestre em Enfermagem. Discente do Programa de PGENF/UFRN, nível Doutorado. Professora Assistente da UFRN. Natal, RN, Brasil. Email:a.elza@uol.com.br.

${ }^{3}$ Enfermeiro. Enfermeiro do Hospital Monsenhor Walfredo Gurgel. Natal, RN, Brasil. E-mail: vamilsonpontes@gmail.com.

${ }^{4}$ Acadêmica do curso de graduação em Enfermagem da UFRN. Natal, RN, Brasil. E-mail: quinidia@hotmail.com.

${ }^{5}$ Enfermeiro, Doutor em Enfermagem Fundamental. Professor Titular da UFRN. Natal, RN, Brasil. E-mail: gvt@ufrnet.br.
} 


\section{INTRODUÇÃO}

Os programas de transplantes de órgãos tiveram seu início no final dos anos de 1940, quase que simultaneamente, em Paris, Londres, Edimburgo e Boston. Contudo, nessa fase ainda não havia o conhecimento de aspectos extremamente importantes para o êxito dos transplantes, relacionados à imunologia e histocompatibilidade ${ }^{(1)}$.

No entanto, com a melhoria das técnicas cirúrgicas, dos cuidados intensivos, da prevenção de infecções, do advento das drogas imunossupressoras e da compreensão da compatibilidade imunológica e rejeição, esses procedimentos passaram da simples experimentação para uma prática médica com grande índice de sucesso ${ }^{(2-4)}$.

No Brasil, os transplantes de órgãos e tecidos tiveram início no ano de 1964, na cidade do Rio de Janeiro, e no ano seguinte na cidade de São Paulo, com a realização dos dois primeiros transplantes renais no país. No entanto, em razão da baixa sobrevida dos pacientes transplantados, esse tipo de tratamento inicialmente teve pouca repercussão(1).

A partir de 1996 o número de transplante de órgãos sólidos tornou-se significativo, havendo a necessidade de criar o Sistema Nacional de Transplante (SNT), a fim de coordenar e regulamentar essa atividade. Para isso foi publicada, em 4 de fevereiro de 1997, a Lei $n^{\circ} 9.434$, que dispõe sobre a retirada de órgãos, tecidos e partes do corpo humano para transplante. Determinando a gratuidade da doação e estabelecendo critérios para o doador vivo e falecido ${ }^{(5-6)}$.

Com esse entendimento, uma pessoa só poderá ser doadora em vida se, após avaliação médica, estiver em boas condições de saúde, for considerada capaz juridicamente e voluntariamente concorde com o ato de doar um órgão duplo, ou parte de um órgão. A lei confere ao cônjuge ou parentes até o quarto grau, ou qualquer outra pessoa, mediante autorização judicial, dispensada no caso da medula óssea, o direito de ser doador ${ }^{(6)}$.

O doador falecido é aquele com diagnóstico confirmado de Morte Encefálica (ME), conforme a resolução estabelecida pelo Conselho Federal de Medicina (CFM), e a doação de seus órgãos e tecidos dependerá da autorização do cônjuge ou parente, maior de idade, obedecida a linha sucessória, reta ou colateral, até o segundo grau. $O$ doador falecido pode simultaneamente, beneficiar oito receptores de órgãos sólidos, além dos tecidos como córneas, ossos, válvulas e pele ${ }^{(6-7)}$.

A efetivação do transplante de órgãos e tecidos com o doador falecido depende do processo de doaçãotransplante, que é dividido em etapas interdependentes, iniciando com a identificação e notificação do Potencial Doador (PD), seguido pela avaliação, manutenção dos parâmetros hemodinâmicos, confirmação do diagnóstico de $M E$, entrevista familiar, documentação de $M E$, aspectos logísticos, remoção e distribuição de órgãos e tecidos, transplante e acompanhamento de resultados ${ }^{(1,8)}$.

Portanto, há igual importância em cada uma dessas etapas, e uma delas permeia todo o processo, que é o cuidado na manutenção dos parâmetros hemodinâmicos do PD, visando à viabilidade dos órgãos para transplantes. Рara tanto, recomenda-se o monitoramento contínuo cardíaco, da saturação de oxigênio, pressão arterial, pressão venosa central, temperatura corporal, do débito urinário, equilíbrio hidroeletrolítico e acidobásico(8-9).

O enfermeiro, junto a equipe de enfermagem, é responsável por realizar, durante o período de manutenção, o controle e registro de todos os parâmetros hemodinâmicos do PD. Contudo, é necessário conhecimento científico acerca das repercussões fisiopatológicas inerentes à $M E$ e dos cuidados necessários para garantir as melhores condições funcionais possíveis dos órgãos e tecidos a serem retirados e transplantados ${ }^{(10-11)}$.

Diante do exposto, objetivou-se com este estudo verificar o conhecimento dos profissionais de enfermagem sobre a morte encefálica e os cuidados na manutenção do potencial doador de órgãos/tecidos para transplantes.

Ressalta-se que o conhecimento sobre a ME é de extrema relevância para o enfermeiro, profissional responsável pela equipe de enfermagem que elabora e supervisiona os cuidado na manutenção do PD, como também para todos os profissionais de saúde que atuam na assistência desse paciente, pois, através desse conhecimento, a assistência pode ser planejada e executada pela equipe.

Dessa forma, espera-se que este estudo possa trazer subsídios para o planejamento de ações que venham melhorar a qualidade da assistência prestada aos PDs, o 
que resultará em maior viabilidade dos órgãos e tecidos e maiores taxas de sucesso dos transplantes.

\section{MÉTODO}

A pesquisa é do tipo exploratório-descritiva, com abordagem quantitativa, realizada nas unidades de emergência e terapia intensiva de um hospital da rede pública de saúde, credenciado pelo SNT para retirada de múltiplos órgãos, em Natal/RN.

A coleta de dados foi realizada nos meses de agosto e setembro de 2010. Utilizou-se a amostragem por acessibilidade, definida como aquela que seleciona elementos pela facilidade de acesso a eles ${ }^{(12)}$. Portanto, dos 120 profissionais de enfermagem que atuam no setor de emergência e UTI, 60 concordaram em participar da pesquisa mediante assinatura do Termo de Consentimento Livre e Esclarecido.

Estabelecemos como critérios de inclusão estar em exercício ativo nesse hospital no período do estudo e trabalhar nas UTIs ou setor de emergência e como critérios de exclusão responder menos de $80 \%$ da parte III do questionário. Após a exclusão dos questionários respondidos de forma incompleta, 55 profissionais fizeram parte da amostra, o que corresponde a $45,8 \%$ do universo.

O instrumento de coleta de dados utilizado foi elaborado pelos próprios pesquisadores, tomando como base os fundamentos preconizados pela literatura científica sobre o assunto(1,3-4,8-11,13-17). O mesmo foi submetido a um pré-teste no grupo de pesquisa Incubadora de Procedimentos de Enfermagem da Universidade Federal do Rio Grande do Norte (UFRN), após um curso de extensão, de oito horas, sobre o processo de doação de órgãos e tecidos para transplante. O questionário sofreu pequenas modificações na sua redação, estruturação, conteúdo, sequência, categorização e codificação das informações, objetivando sua melhor aplicabilidade e adequação aos propósitos do estudo.

Após esse processo de testagem e adequação, o instrumento ficou composto pelas seguintes partes: parte I contém dados de identificação pessoal, como: idade, sexo, grau de instrução. Na parte II estão os dados de identificação profissional, como: formação profissional, tempo de serviço na enfermagem, setor de trabalho, instituição de formação profissional básica (pública ou privada), curso de aperfeiçoamento e/ou especialização. A parte III é formada de perguntas abertas relacionadas à assistência de Enfermagem ao PD em ME, como: trabalha ou já trabalhou com este tipo de paciente?; sente-se preparado para assistir a estas vítimas?; onde adquiriu estas informações?; existe algum empecilho considerado importante que dificulte assistir a estes pacientes?; quais são e como tenta solucioná-los? A parte III consta de 10 perguntas de múltipla escolha, algumas delas com mais de uma opção correta, relativas ao protocolo e fisiopatologia da ME e aos cuidados com a manutenção do PD.

A coleta de dados foi realizada pelos pesquisadores. Os dados oriundos das questões fechadas do instrumento foram organizados em uma planilha eletrônica, sendo apresentados em tabelas, com frequência relativa e absoluta. As questões abertas foram submetidas a análise temática de conteúdos, que prevê a organização das informações por meio da préanálise, exploração do material, tratamento dos resultados e interpretação(18). As categorias empíricas emergidas foram processadas eletronicamente e apresentadas em forma de tabelas. Para tanto, utilizouse a estatística descritiva e o software Microsoft-Excel XP.

Foram obedecidos todos os princípios éticos e legais que regem a pesquisa em seres humanos, preconizados na Resolução do Conselho Nacional de Saúde No 196/96, manifestado pela aprovação do protocolo do registro do Comitê de Ética e Pesquisa da Universidade Federal do Rio Grande do Norte (CEP-UFRN) 414/10.

\section{RESULTADOS}

Participaram do estudo 55 profissionais e, desses, $25,5 \%$ eram enfermeiros e $74,5 \%$ técnicos em enfermagem. A maioria era do sexo feminino (92,7\%), com nível médio de instrução $(56,4 \%)$. Dos técnicos em enfermagem, 18,1\% tinham nível superior. A faixa etária predominante foi entre 21 e 30 anos (32,7\%), com média de idade de 27,4 anos. Sobre o tempo de serviço, sobressaiu entre 10 e 14 anos (23,6\%). A maioria (58,2\%) não possuía nenhum curso de especialização ou aperfeiçoamento (Tabela 1 ). 
Tabela 1: Caracterização sociodemográfica e laboral dos profissionais de enfermagem da Unidade de Terapia Intensiva e Setor de Emergência. Natal, RN, 2010

\begin{tabular}{|c|c|c|c|}
\hline \multicolumn{2}{|c|}{ Caracterização sociodemográfica e laboral } & \multirow{2}{*}{$\frac{\mathbf{N}}{41}$} & \multirow{2}{*}{$\begin{array}{c}\% \\
74,5\end{array}$} \\
\hline Caron/Funcão & Técnico em Enfermagem & & \\
\hline Largo/runçao & Enfermeiro & 14 & 25,5 \\
\hline \multirow{3}{*}{ Sexo } & Feminino & 51 & 92,7 \\
\hline & Masculino & 4 & 7,3 \\
\hline & $21-30$ anos & 18 & 32,7 \\
\hline \multirow{3}{*}{ Faixa etária } & $31-40$ & 14 & 25,5 \\
\hline & $41-50$ & 11 & 20,0 \\
\hline & Não informaram & 12 & 21,8 \\
\hline \multirow{3}{*}{ Nível de escolaridade } & Ensino Médio & 31 & 56,4 \\
\hline & Ensino Superior & 24 & 43,6 \\
\hline & $<1$ ano & 11 & 20,0 \\
\hline \multirow{5}{*}{ Tempo de serviço } & $1-4$ anos & 9 & 16,4 \\
\hline & $5-9$ anos & 8 & 14,5 \\
\hline & $10-14$ anos & 13 & 23,6 \\
\hline & 15 a 20 anos & 7 & 12,7 \\
\hline & $>20$ anos & 7 & 12,7 \\
\hline \multirow{2}{*}{ Especialização/aperfeiçoamento } & Sim & 23 & 41,8 \\
\hline & Não & 32 & 58,2 \\
\hline \multirow{2}{*}{ Trabalha ou já trabalhou com PDs de órgãos/tecidos } & Sim & 43 & 78,2 \\
\hline & Não & 12 & 21,8 \\
\hline \multirow{2}{*}{ Se sente preparado para assistir aos PDs } & Sim & 32 & 58,2 \\
\hline & Não & 23 & 41,8 \\
\hline \multirow{2}{*}{ Existem empecilhos que dificulte a assistência ao PD } & Sim & 34 & 61,8 \\
\hline & Não & 21 & 38,2 \\
\hline
\end{tabular}

A maior parte dos respondentes $(78,2 \%)$ informou que já haviam trabalhado com PDs de órgãos e tecidos para transplante, e 52,2 afirmaram estar preparados para cuidar desses pacientes. Quanto a forma de obtenção de conhecimento para assistir aos PDs, informaram ter adquirido em palestras (37,5\%), cursos específicos $(34,4 \%)$, prática $(18,8 \%)$ e outras formas (9,3\%).

A maioria dos entrevistados $(61,8 \%)$ afirmou que há empecilhos que dificultam a assistência ao PD. Dentre eles, mencionaram o despreparo da equipe (34,6\%); falta de materiais $(23,1 \%)$ e de estrutura adequada $(19,2 \%)$; demora na abertura do protocolo para confirmação da ME (11,6\%); recusa familiar $(7,7 \%)$; e equipe insuficiente (3,8\%).

Quanto às soluções para esses empecilhos, citaram a improvisação de ações para suprir a falta de materiais e de estrutura adequada (26,3\%); participação em cursos específicos (26,3\%); orientação à equipe sobre os cuidados de manutenção ao PD (15,8\%); orientação à família sobre o processo de doação $(15,8)$; e estabelecimento de protocolos visando à melhoria da assistência ao PD (10,5\%) e campanhas de informação sobre a doação de órgãos (5,3\%).
A seguir, será apresentado os dados dos pesquisados quanto ao nível de conhecimento relacionado à ME e aos cuidados com a manutenção do PD (Tabelas 2 e 3). Ressalta-se que alguns questionamentos tinham mais de uma alternativa correta. 
Tabela 2: Conhecimento dos profissionais de enfermagem sobre a morte encefálica. Natal, RN, 2010.

\begin{tabular}{|c|c|c|c|}
\hline \multicolumn{2}{|c|}{ Conhecimento dos profissionais de enfermagem sobre a morte encefálica } & \multirow{2}{*}{$\begin{array}{l}\mathbf{N} \\
27\end{array}$} & \multirow{2}{*}{$\begin{array}{c}\% \\
49,1\end{array}$} \\
\hline \multirow{3}{*}{$\begin{array}{l}\text { Condições indispensáveis para a abertura } \\
\text { do protocolo de ME }\end{array}$} & $\begin{array}{c}\text { Temperatura superior a } 36^{\circ} \mathrm{C} \text {, ausência de depressores do SNC } \\
\text { nas últimas } 48 \text { horas. }\end{array}$ & & \\
\hline & Causa de ME definida, sem uso de sedação & 26 & 47,2 \\
\hline & $\begin{array}{c}\text { Causa de ME conhecida, sódio sérico dentro dos parâmetros de } \\
\text { normalidade }\end{array}$ & 12 & 21,8 \\
\hline \multirow{7}{*}{ Condições que inviabilizam a doação } & Potássio sérico normal e causa de morte não conhecida & 2 & 3,6 \\
\hline & Infecção pelo vírus HTLV & 34 & 61,8 \\
\hline & Tuberculose pulmonar & 27 & 49,1 \\
\hline & Tumores primários do sistema nervoso central & 13 & 23,6 \\
\hline & Encefalite hérpética & 13 & 23,6 \\
\hline & Câncer de colo de útero in situ & 10 & 18,2 \\
\hline & Câncer de pele não-melanoma & 7 & 12,7 \\
\hline \multirow{9}{*}{ Alterações fisiológicas associadas à ME } & Alteração da temperatura corporal & 26 & 47,2 \\
\hline & Instabilidade hemodinâmica & 24 & 43,6 \\
\hline & Hipoperfusão tecidual & 12 & 21,8 \\
\hline & Hipóxia cerebral & 11 & 20,0 \\
\hline & Distúrbio metabólico & 11 & 20,0 \\
\hline & Alteração da coagulação & 11 & 20,0 \\
\hline & Lesão cerebral & 8 & 14,5 \\
\hline & Disfunção hipotalâmica & 7 & 12,7 \\
\hline & Distúrbios hormonais & 3 & 5,5 \\
\hline \multirow{4}{*}{ Funções encefálicas ausentes } & Perda irreversível de toda a função cortical e de tronco cerebral & 28 & 50,9 \\
\hline & Desconhece & 23 & 41,8 \\
\hline & Perda irreversível de toda a função cortical cerebral & 16 & 29,1 \\
\hline & Variável conforme a lei & 7 & 12,7 \\
\hline
\end{tabular}

Tabela 3: Conhecimento dos profissionais de enfermagem sobre a manutenção do potencial doador. Natal, RN, 2010.

\begin{tabular}{|c|c|c|c|}
\hline \multicolumn{2}{|c|}{ Conhecimento dos profissionais de enfermagem sobre a manutenção do potencial doador } & \multirow{2}{*}{$\frac{\mathbf{N}}{34}$} & \multirow{2}{*}{$\begin{array}{c}\% \\
61,8\end{array}$} \\
\hline & Soro aquecido & & \\
\hline Forma mais rápida, eficaz e econômica de & Manta térmica & 21 & 38,2 \\
\hline & Cobertores & 18 & 32,7 \\
\hline \multirow{6}{*}{ Manejo dos distúrbios hidroeletrolíticos } & Aquecimento do ar inspirado na ventilação mecânica & 2 & 3,6 \\
\hline & Reposição de sódio, potássio e magnésio & 28 & 50,9 \\
\hline & Correção da acidose metabólica com reposição de bicarbonato & 13 & 23,6 \\
\hline & Reposição de água livre e uso de análogo do ADH & 10 & 18,2 \\
\hline & Uso de soluções hipertônicas & 6 & 10,6 \\
\hline & Deve ser protegida com gaze & 32 & 58,2 \\
\hline \multirow[t]{2}{*}{ Proteção da córnea } & Deve ser protegida com pomada & 20 & 36,3 \\
\hline & Deve ser fechado o olho com esparadrapo & 6 & 10,9 \\
\hline \multirow{2}{*}{ PD pode ser reanimado } & $\operatorname{Sim}$ & 29 & 52,7 \\
\hline & Não & 26 & 47,3 \\
\hline \multirow{3}{*}{$\begin{array}{l}\text { Condutas adotadas pelo médico após a } \\
\text { conclusão do protocolo de ME }\end{array}$} & $\begin{array}{c}\text { Interromper as medidas de suporte caso a família recuse a } \\
\text { doação dos órgãos }\end{array}$ & 28 & 50,9 \\
\hline & Emitir declaração de óbito somente se houver parada cardíaca & 16 & 29,0 \\
\hline & $\begin{array}{c}\text { Emitir declaração de óbito no mesmo horário do exame } \\
\text { confirmatório da morte encefálica }\end{array}$ & 5 & 9,1 \\
\hline
\end{tabular}

No que se refere as condições indispensáveis para a abertura do protocolo de ME, 49,1\% dos entrevistados acreditavam ser a temperatura superior a $36^{\circ} \mathrm{C}$ e a ausência de depressores do Sistema Nervoso Central (SNC) nas últimas 48 horas; 47,2\% afirmaram sobre a causa de morte definida, sem uso de sedação; $21,8 \%$ confirmaram que seria a causa de morte conhecida e sódio sérico dentro dos parâmetros de normalidade; e apenas 3,6\% mencionaram o potássio sérico normal e causa de morte não conhecida.

Nas condições que inviabilizam a doação de órgãos e tecidos havia seis opções de escolha. Dessas, as mais 
aludidas foram a infecção pelo vírus Human $T$ lymphotropic virus (HTLV) (61,8\%), a tuberculose pulmonar $(49,1 \%)$, seguidas de tumores primários do SNC e encefalite herpética com o mesmo percentual $(23,6 \%)$. Outras causas, como câncer de colo de útero in situ (18,2\%) e câncer de pele não melanoma (12,7\%), apesar de não inviabilizarem a doação, também foram citadas.

Quanto às alterações fisiológicas associadas à $M E$, observa-se que a alteração da temperatura corporal $(47,2 \%)$, e a instabilidade hemodinâmica $(43,6 \%)$, foram as mais citadas. No entanto, algumas opções que não se caracterizam como alterações decorrentes da ME, mas que se evidenciam em decorrência da mesma, como hipóxia cerebral $(20,0 \%)$ e lesão cerebral (14,5\%), também foram apontadas como corretas.

Em relação às funções encefálicas ausentes no paciente em ME, das quatro opções disponíveis para essa pergunta, a maioria respondeu corretamente sobre a perda irreversível de todas as funções do córtex cerebral, telencéfalo e de tronco cerebral $(50,9 \%)$. Um grande número de participantes $(41,8 \%)$ desconhecia a resposta a essa questão. Outros profissionais optaram erroneamente pela alternativa de perda irreversível de toda a função cortical cerebral (29,1\%). Alguns pesquisados $(12,7 \%)$, afirmaram incorretamente que essas funções variam conforme a legislação de cada país.

No tocante aos cuidados de manutenção ao PD de órgãos e tecidos para transplante (Tabela 3), foi questionado sobre a forma mais rápida, eficaz e econômica de aquecer esse paciente, e 61,8\% dos pesquisados responderam corretamente em relação à infusão de soro aquecido.

Sobre as intervenções mais importantes no manejo dos distúrbios hidroeletrolíticos do PD, havia quatro opções. Dessas, obteve maior percentual a alternativa incorreta sobre a reposição de sódio, potássio e magnésio, com 50,9\%. No entanto, a opção correta, que seria a reposição de água livre e uso de análogo do Hormônio Antidiurético (ADH), só correspondeu apenas $18,2 \%$ dos acertos.

Em relação aos cuidados na proteção da córnea, o maior número, 58,2\% dos respondentes, escolheu a opção incorreta quanto à proteção da córnea com gaze.

Quando se questionou se, em caso de parada cardíaca, o PD poderia ser reanimado, 52,7\% dos profissionais responderam corretamente que sim.
Quando questionados quanto ao porquê, a maioria dos que responderam $\operatorname{sim}(71,4 \%)$ afirmou que ега рага manter a viabilidade dos órgãos a serem doados. Os que responderam negativamente, na sua maioria $(58,8 \%)$ informaram que não podia ser reanimado porque o mesmo já se encontrava morto.

Quanto as condutas a serem adotadas pelo médico após a conclusão do protocolo de ME, 50,9\% afirmaram corretamente sobre interromper as medidas de suporte caso a família recuse a doação dos órgãos. Porém, 29,0\% optaram incorretamente sobre emitir a declaração de óbito somente se houver parada cardíaca, e apenas 9,1\% afirmaram de forma correta sobre a emissão da declaração de óbito no mesmo horário do exame confirmatório da ME.

\section{DISCUSSÃO}

No presente estudo, tentou-se avaliar o conhecimento dos profissionais de enfermagem relacionados à $\mathrm{ME}$ e aos cuidados na manutenção do PD de órgãos e tecidos para transplante.

Entre os intensivistas havia uma predominância do sexo feminino e da faixa etária entre 21 e 30 anos. Dados semelhantes foram encontrados em pesquisas com profissionais de enfermagem, onde a maioria dos inquiridos era do sexo feminino $(51,8 \%)$, com faixa etária semelhante (70,6\%), mostrando que no Brasil e em outros países o pessoal de enfermagem é relativamente jovem, estando a maioria na faixa mais produtiva de suas vidas. Em relação à predominância do feminino (92,7\%), esta realidade da enfermagem no hospital investigado coincide com a de vários estudos realizados no país(10-11).

A maior parte dos participantes (58,2\%) afirmou estar preparada para atender aos PDs. No entanto, quando relacionado ao número de acertos, observou-se que esta não é a realidade. Levando em consideração esses dados, constatou-se a premência de um treinamento específico que venha suprir a defasagem detectada no conhecimento desses sujeitos acerca da assistência aos PDs. Tal fato evidencia que a educação com a participação dos profissionais de saúde e da sociedade é um dos fatores determinantes para o sucesso ou o fracasso dos programas de transplantes. Ao retratar a importância de programas de educação permanente, a equipe de enfermagem é citada como elemento fundamental em todo o contexto do procedimento, uma vez que a aprendizagem significa 
mudança no comportamento da pessoa devido à incorporação de novos hábitos, atitudes, conhecimentos e destrezas ${ }^{(19)}$.

A atuação do enfermeiro na detecção precoce de pacientes com critérios para abertura do protocolo de ME é fundamental para possibilitar o diagnóstico e a conclusão de todas as etapas em tempo hábil, de forma a garantir a viabilidade dos órgãos para transplantes ${ }^{(14)}$.

Sobre a existência de empecilhos que dificultam a assistência aos PDs, citada pela maioria (61,8\%) dos entrevistados, evidencia-se que o cuidado a esses pacientes está intrinsecamente comprometido; entretanto, é importante salientar que o conhecimento prévio sobre o assistir aos PDs, associado à vontade de fazer, ofusca os "empecilhos"(13).

O principal empecilho citado pela enfermagem é o despreparo da equipe (34,6\%). Esse problema pode gerar ansiedade, estresse e maior desgaste físico, ocasionando sérios prejuízos de saúde para o cuidador e para quem recebe os cuidados. Entende-se que o despreparo da equipe, além de gerar todos os problemas já referidos, compromete a eficácia e gera desemprego. O trabalhador, para manter-se empregável, necessita de uma contínua atualização(13-14).

No Brasil, a ME será definida naqueles pacientes que apresentarem a seguinte tríade diagnóstica: coma arreativo e arresponsivo, ausência de reflexos supra espinhais (ou seja, todos os reflexos de tronco encefálico) e apneia frente à hipercarbia (elevação da pressão parcial de $\mathrm{CO} 2)^{(9)}$.

Dessa forma, é imprescindível que a equipe de enfermagem que trabalha nos setores que recebem esses pacientes conheça as alterações fisiológicas decorrentes da ME para que, junto com a equipe médica, possa identificar precocemente um paciente com critérios clínicos de $\mathrm{ME}$, realizar um diagnóstico seguro e conduzir, de maneira adequada, o manuseio do PD. A literatura descreve que, quando não há o preparo adequado do paciente com suspeita de $M E$, a taxa de complicações durante a avaliação clínica pode chegar a $60 \%$, o que se reduz a $7 \%$ com preparo adequado ${ }^{(16)}$.

No que concerne ao diagnóstico de $M E$, este deve respeitar todas as orientações da Resolução $n^{\circ}$ 1.480/97 do Conselho Federal de Medicina (CFM), para todos os pacientes com suspeita de $M E$, independentemente da possibilidade de doação de órgãos ${ }^{(7)}$.
Dentre as condições indispensáveis para a abertura do protocolo de ME, apesar da maioria dos participantes ter escolhido a opção errada sobre a temperatura superior a $36^{\circ} \mathrm{C}$ e a ausência de depressores do SNC nas últimas 48 horas, alguns (47,2\%) afirmaram corretamente sobre ser imprescindível a definição da causa de morte e a suspensão do uso de sedativos. 0 que corresponde dizer que deve haver causa estrutural, de etiologia conhecida, que possa ser registrada e que tenha caráter de irreversibilidade. Via de regra, todo paciente com suspeita de ME deve realizar uma tomografia de crânio. Obrigatoriamente as situações que mimetizem o coma ou a falência de atividade neurológica, devem ser afastadas ${ }^{(16)}$.

Devem-se afastar o uso de sedativos ou bloqueadores da junção neuromuscular, como drogas de abuso ou fármacos depressores do SNC, que podem alterar a avaliação do exame neurológico, comprometendo o diagnóstico nos pacientes comatosos. Dentre as várias situações, encontram-se pacientes em pós-operatório de neurocirurgias, pós-tratamento com barbitúricos por estado de mal epiléptico, sob ação de agentes paralisantes (curares) ou agentes derivados de morfina ou outros sedativos. Logo, é obrigatório descartar a presença do efeito de substâncias depressoras do SNC ${ }^{(16)}$.

O tempo necessário para a metabolização das diferentes drogas varia em função do

tipo, quantidade e tempo de administração. Não se aplicam regras fixas: cada droga tem um tempo necessário a sua metabolização, conforme o tempo de ação, presença de situação de estado de equilíbrio, disfunção hepática ou renal, idade, presença de gravidez e atividade de seus subprodutos. Na impossibilidade de obtenção de níveis séricos, deve-se respeitar o tempo de vida média de cada fármaco ou droga de abuso(16).

Como pré-requisito à avaliação neurológica deve-se afastar a hipotermia, que pode ser causa do coma, pois a manutenção da temperatura corporal depende da ativação do hipotálamo anterior. Em situações de $M E$, com a perda desse centro termorregulador, produz-se hipotermia progressiva, comprometendo o fluxo sanguíneo cerebral. Dependendo da intensidade da hipotermia, pode ser observada a perda da autorregulação cerebral, a perda do reflexo fotomotor e a abolição dos reflexos tendíneos. Assim, é necessário considerar a temperatura mínima para o início do exame 
neurológico. Temperaturas abaixo de $35^{\circ} \mathrm{C}$ são inaceitáveis, segundo os critérios do Royal College of Surgeons. Portanto, a temperatura tem que estar superior a $35^{\circ} \mathrm{C}$, e não $36^{\circ} \mathrm{C}$ como foi relatado por muitos entrevistados $(49,1 \%)^{(16)}$.

Dessa forma, as condições indispensáveis para a abertura do protocolo de ME são a causa do coma definida, temperatura superior a $35^{\circ} \mathrm{C}$ e a não utilização de drogas depressoras do SNC(10).

A adequada avaliação clínica laboratorial do PD de órgãos e tecidos é fundamental para a obtenção de um enxerto de qualidade, assim como precisa ser evitada a transmissão de enfermidades infecciosas ou neoplásicas. Atualmente são poucas as condições que inviabilizam a doação de órgãos e tecidos para transplante e, dentre essas, estão os tumores malignos, com exceção dos carcinomas basocelulares da pele, carcinoma in situ do colo uterino e tumores primitivos do SNC. Outras contraindicações são as sorologias positivas para HIV ou para HTLV I e II, sepse ativa e não controlada, e tuberculose ativa ${ }^{(9)}$.

A ME é um processo complexo que altera de forma dramática a fisiologia e a bioquímica celulares de todos os sistemas orgânicos. A síndrome clínica da ME produz instabilidade hemodinâmica, hipoperfusão tecidual, hipotermia, coagulopatia, distúrbio metabólico e hormonal. É um estado inflamatório que leva a perturbações celulares e moleculares, capazes de afetar a função dos órgãos potencialmente disponíveis para transplante ${ }^{(8,15)}$.

É importante enfatizar que o conceito de ME não parecia claro para alguns profissionais, quando colocaram a lesão cerebral (14,5\%), disfunção hipotalâmica $(12,7 \%)$ e hipóxia cerebral $(20,0 \%)$ como eventos fisiopatológicos decorrentes da ME. A morte encefálica (ME) é definida como parada completa e irreversível das funções encefálicas, impossibilitando a manutenção dos órgãos sem o auxilio de meios artificiais. Portanto, na ME essas funções já não existem, o indivíduo já se encontra morto, e o que vai aparecer são inúmeras complicações decorrentes da parada do encéfalo(o,15).

No Brasil, define-se a situação de ME como a cessação irreversível das funções do encéfalo, ou seja, do córtex cerebral, telencéfalo e tronco cerebral, determinada por uma catástrofe sobre a parte central do sistema nervoso ${ }^{(7)}$. É importante enfatizar o grande número de participantes (41,8\%) que desconhecia a resposta a essa questão, e os que optaram incorretamente sobre a alternativa de perda irreversível de toda a função cortical cerebral $(29,1 \%)$ além de outros $(12,7 \%)$ que afirmaram erroneamente que essas funções variam conforme a legislação de cada país.

Nos cuidados para a manutenção do PD é importante salientar o controle da temperatura corpórea, aquecer o PD com cobertores, se possível manta térmica, ou com focos de luz direcionados para o tórax ou abdome; este é um cuidado fundamental, pois a ME ocasiona dano ao centro termorregulador hipotalâmico, que, além da hipotermia, pode gerar depressão do miocárdio, arritmias, diminuição do transporte de oxigênio, aumento da afinidade da hemoglobina pelo oxigênio, disfunção renal, pancreatite e coagulopatias ${ }^{(8,15)}$.

No entanto, aquecer os fluidos endovenosos a temperaturas de $37^{\circ}-38^{\circ} \mathrm{C}$ é o cuidado mais relevante e eficaz para controlar a temperatura corporal. Apesar da maioria dos pesquisados ter afirmado sobre esses cuidados, alguns $(38,2 \%)$ mencionaram a manta térmica, apesar de ser um material dispendioso e inexistente na unidade hospitalar estudada(10).

Sobre as intervenções mais importantes no manejo dos distúrbios hidroeletrolíticos do PD, a alternativa incorreta sobre a reposição de sódio, potássio e magnésio obteve maior percentual (50,9\%). Ficando a opção correta com apenas $18,2 \%$ dos acertos, referente à reposição de água livre e uso de análogo do Hormônio Antidiurético (ADH) ${ }^{(10)}$.

As anormalidades hidroeletrolíticas são comuns, e as mais frequentes são alcalose respiratória, hipocalemia, hipercalemia, hipernatremia, hipofosfatemia e acidose metabólica. Diabetes insipidus é a causa mais comum de hipernatremia, condição em que o sódio é maior que 150 $\mathrm{mmol} / \mathrm{L}$, estando indicada a infusão de água livre via sonda nasogástrica ou solução de sódio a 0,45\%. Níveis de sódio maiores que $155 \mathrm{mmol} / \mathrm{L}$ estão relacionados com disfunção hepática e perda do enxerto no receptor. Conexa à correção do sódio, deve-se proceder a normalização sérica dos demais eletrólitos ${ }^{(17-18)}$.

Estudos demonstram que o uso de vasopressina está associado à melhora da função dos enxertos renal, pulmonar e cardíaco, razão pela qual alguns autores recomendam seu uso como fármaco vasopressor de primeira escolha no manuseio de PD. Em alguns casos 
pode ser preciso associar a 1-D-amino-8-argininavasopressina (DDAVP), que tem efeito antidiurético muito mais potente ${ }^{(17-18)}$.

No que se refere aos cuidados na proteção da córnea, a literatura demonstra que cuidar das córneas através da umidificação é fundamental, pois esse tecido pode ser facilmente lesionado pelo ressecamento, devendo a córnea ser umedecida e protegida com pomada para evitar ceratites ${ }^{(16-17)}$. A maior parte dos respondentes $(58,2 \%)$ optou sobre a resposta incorreta quanto à proteção da córnea com gaze.

Aproximadamente $10 \%$ de todos os PDs experimentam parada cardíaca que necessita de ressuscitação cardíaca durante a fase de manutenção. As manobras ressuscitadoras básicas e avançadas imediatas precisam seguir os protocolos tradicionalmente estabelecidos. Deve-se lembrar que a bradicardia não responde à atropina na presença de $M E$, sendo necessário utilizar estimulantes B-adrenérgicos ou marcapasso nessa condição. Portanto, deve-se realizar a ressuscitação cardíaca no PD, e, apesar da maioria ter respondido corretamente, chamamos a atenção para o grande percentual $(47,3 \%)$ que respondeu que o PD não pode ser reanimado ${ }^{(10-11)}$.

Uma vez completado o processo de determinação da $\mathrm{ME}$, todos os exames realizados, incluindo as gasometrias e exames laboratoriais, devem ser registrados no prontuário do paciente, e o Termo de Declaração de ME deve ser preenchido e assinado pelos médicos que participaram no processo. Do ponto de vista médico e legal, a ME do paciente corresponde à morte, ainda que ele esteja com suas condições cárdiopulmonares mantidas artificialmente. Portanto, a hora que deve constar no atestado de óbito, de acordo com o Parecer do CREMESP $n^{\circ}$. 29.650/95, é a hora da confirmação por exame complementar, ou seja, a determinação de $M E^{(16)}$.

Pacientes vítimas de morte violenta podem ser avaliados como potenciais doadores e, se houver consentimento familiar, ocorre a retirada dos órgãos, devendo o corpo ser encaminhado para o Instituto Médico Legal (IML) para necropsia. Nesses casos, o atestado de óbito é fornecido pelo IML. Todo o material referente à caracterização da ME e da doação de órgãos, ou seja, prontuários, fichas, laudos de exames, filmes e avaliações, deve ser arquivado por um período de 20 $\operatorname{anos}^{(16)}$.
Após a confirmação de $M E$, a retirada de suporte de vida é um dever ético da equipe médica, pois a manutenção de suporte vital nesses casos não traz benefício, além de gerar sofrimento à família e gastos desnecessários. É possível que, de forma a evitar uma situação de conflito, a equipe médica possa optar pela manutenção do suporte de vida até que "espontaneamente" ocorra a parada cardíaca, com ordem de não reanimar ${ }^{(10-11)}$.

Após a ME, mesmo quando todo suporte é mantido, a parada cardíaca ocorre ao redor de uma semana. Entretanto, existem casos descritos em que esses pacientes permaneceram gerando gastos e ocupando leitos de UTI por quase dois meses. O que deve ser questionado, nessa situação, é a quem essa equipe estaria beneficiando com a postergação da retirada do suporte vital de um indivíduo já definido como morto. 0 simples fato de evitar enfrentar uma "possível situação de conflito" não parece ser uma explicação aceitável do ponto de vista ético(17).

\section{CONCLUSÃO}

O diagnóstico de ME precisa ser entendido e conhecido por todos os profissionais de saúde. O conhecimento prático e científico atual sobre os cuidados de manutenção ao $\mathrm{PD}$, no que se refere aos profissionais de enfermagem, é insuficiente, pouco e superficial. Existe a necessidade de educação e aperfeiçoamento sobre o tema, a fim de evitar gastos desnecessários, estresse profissional, sofrimento familiar, além de possibilitar o aumento da oferta de órgãos e tecidos para transplantes, gerando benefícios a toda sociedade.

A possibilidade da doação de órgãos e tecidos representa uma dicotomia entre a tristeza da morte e a perspectiva do recomeço de uma vida com qualidade. É nesse sentido que a familiaridade com os conceitos de $\mathrm{ME}$, sua identificação rigorosa e correta, e principalmente as condutas adequadas com relação à manutenção do PD devem ser destacadas, para que possa ser obtida uma ampliação do conhecimento científico sobre essa questão. 


\section{REFERÊNCIAS}

1. Associação Brasileira de Transplante de Órgãos. Diretrizes básicas para captação e retirada de múltiplos órgãos e tecidos da Associação Brasileira de Transplante de Órgãos. São Paulo: ABTO; 2009.

2. Lago P, Piva J, Garcia PC, Troster E, Bousso A, Sarno MO, et al. Brain death: medical management in seven Brazilian pediatric intensive care units. J Pediatr. 2007;83(2): 133-140.

3. Silva MSJ, Teixeira JB, Nóbrega MFB, Carvalho SMA. Nursing diagnosis identified in renal transplant patients of a teaching hospital. Rev. Eletr. Enf. [Internet]. 2009 [cited 2012 jun 21]; 11(2):309-17. Available from:

http://www.fen.ufg.br/revista/v11/n2/v11n2a11.htm. 4. Padilha KG, Vattimo MFF, Silva SC, Kimura M. Enfermagem em UTI: cuidando do paciente crítico. São Paulo: Manole; 2010.

5. Lei N. 9.434, de 04 de fevereiro de 1997. Dispõe sobre a remoção de órgãos, tecidos e partes do corpo humano para fins de transplante e tratamento e dá outras providências. Diário Oficial da União (Brasília). 1997 Jul 01.

6. Lei N. 10.211, 23 março de 2001. Altera dispositivos da Lei n. 9.434 , de 4 de fevereiro de 1997, que dispõe sobre a remoção de órgãos, tecidos e partes do corpo humano para fins de transplante e tratamento. 2001 Mar 23.

7. Conselho Federal de Medicina. Resolução CFM-1.480/1997.

Critérios para Diagnóstico de Morte Encefálica. Brasília (Brasil): CFM; 1997.

8. Guetti NR, Marques IR. Nursing assistance to the potential organ donor with brain death. Rev Bras Enferm. 2008;61(1):91-7.

9. Westphal GA, Filho MC, Vieira KD, Zaclikevis VR, Bartz MCM, Wanzuita R, et al. Guidelines for potential multiple organ donors (adult). Part I. Overview and hemodynamic support. Rev Bras Ter Intensiva. 2011;23(3):255-268.

10. Guido LA, Linch GFC, Andolhe R, Conegatto CC, Tonini CC. Stressors in the nursing care delivered to potential organ donors. Rev. Latino-Am. Enfermagem. 2009;17(6): 1023-9.

11. Lemes MMDD, Bastos MAR. The maintenance care of potential organ donors: ethnographic study on the experience of a nursing team. Rev. Latino-Am. Enfermagem. 2007;15(5):986-991.

12. Vergara SC. Projetos e Relatórios de Pesquisa em Administração. São Paulo: Editora Atlas; 2003. 96p.

13. Rech TH, Rodrigues FEM. Care of the potential organ donor. Rev Bras Ter Intensiva. 2007;19(2):197-204.

14. Vilibor RA. Diagnóstico de Morte Encefálica. In: Anais do III Simpósio Internacional de Doação de Órgãos e Tecidos para Transplante da Santa Casa de São Paulo. São Paulo 2009. 15. Domingos GR, Boer LA, Possamai FP. Doação e captação de órgãos de pacientes com morte encefálica. Enfermagem Brasil. 2010;9(4).

16. Westphal GA, Filho MC, Vieira KD, Zaclikevis VR, Bartz MCM, Wanzuita $R$, et al. Diretrizes para manutenção de múltiplos órgãos no potencial doador falecido. Associação de medicina intensiva brasileira. Revista Brasileira de Terapia Intensiva. Obra conjunta. AMIB 2011.

17. Patricia ML, Jefferson $P$, Pedro CG, Eduardo T, Albert $B$, Maria OS, et al. Brain death: medical management in seven Brazilian pediatric intensive care units. J Pediatr, 2007; 83(2):133-140. 18. Cavalcante E, Farias GM, Santos KN. Conhecimento da equipe de enfermagem no processo de cuidar às vítimas de traumatismo raquimedular. InterSiencePlace. 2009; 2:6.

19. Bardin L. Análise de conteúdo. 3rd ed. Lisboa: Edições 70; 2004.

Artigo recebido em 07/06/2011.

Aprovado para publicação em 17/04/2012.

Artigo publicado em 31/12/2012. 